\title{
Acute and subchronic dermal toxicity of nanosilver in guinea pig
}

This article was published in the following Dove Press journal:

International Journal of Nanomedicine

28 April 201 I

Number of times this article has been viewed

\section{Korani' \\ SM Rezayat ${ }^{1,2,4}$ \\ K Gilani ${ }^{3}$ \\ S Arbabi Bidgoli ${ }^{4}$ \\ S Adeli' \\ 'Department of Pharmacology, Faculty of Medicine, Tehran University of Medical Sciences; ${ }^{2}$ Department of Nanotechnology, Faculty of Advanced Sciences and Technology in Medicine, Tehran University of Medical Sciences; ${ }^{3}$ Department of Pharmaceutics, Faculty of Pharmacy, Tehran University of Medical Sciences; ${ }^{4}$ Department of Toxicology \& Pharmacology, Faculty of Pharmacy, Pharmaceutical Sciences Branch, Islamic Azad University (IAUPS), Tehran, Iran}

Correspondence: Seyed Mahdi Rezayat Department of Pharmacology, Tehran University of Medical Sciences (TUMS), Tehran, PO Box 645I-I4I55, Iran

$\mathrm{Tel} / \mathrm{Fax}+982166402569$

Email rezayat@tums.ac.ir
Abstract: Silver has been used as an antimicrobial agent for a long time in different forms, but silver nanoparticles (nanosilver) have recently been recognized as potent antimicrobial agents. Although nanosilver is finding diverse medical applications such as silver-based dressings and silver-coated medical devices, its dermal and systemic toxicity via dermal use has not yet been identified. In this study, we analyzed the potential toxicity of colloidal nanosilver in acute and subchronic guinea pigs. Before toxicity assessments, the size of colloidal nanosilver was recorded in sizes $<100 \mathrm{~nm}$ by $\mathrm{X}$-ray diffraction and transmission electron microscopy. For toxicological assessments, male guinea pigs weighing 350 to $400 \mathrm{~g}$ were exposed to two different concentrations of nanosilver $(1000$ and $10,000 \mu \mathrm{g} / \mathrm{mL})$ in an acute study and three concentrations of nanosilver $(100,1000$, and $10,000 \mu \mathrm{g} / \mathrm{mL})$ in a subchronic study. Toxic responses were assessed by clinical and histopathologic parameters. In all experimental animals the sites of exposure were scored for any type of dermal toxicity and compared with negative control and positive control groups. In autopsy studies during the acute test, no significant changes in organ weight or major macroscopic changes were detected, but dose-dependent histopathologic abnormalities were seen in skin, liver, and spleen of all test groups. In addition, experimental animals subjected to subchronic tests showed greater tissue abnormalities than the subjects of acute tests. It seems that colloidal nanosilver has the potential to provide target organ toxicities in a dose- and time-dependent manner.

Keywords: nanosilver, acute dermal toxicity, subchronic dermal toxicity

\section{Introduction}

The increase in the applications of manufactured nanoparticles, which are composed mostly of metal and metal oxides, is increasing the potential for exposure among manufacturers and consumers. ${ }^{1}$ The major toxicological concern associated with manufactured nanomaterials is that some of are redox active, and some particles are transported across cell membranes and interact with subcellular organelles. ${ }^{2}$ Thus, evaluation of their toxicity on acute and subchronic exposure is essential.

The medical use of silver dates back centuries. Many of the industrial silver compounds, including nitrate, chloride, bromide, acetate, oxide, sulfate, and cyanide, ${ }^{3}$ can be released in to the environment from various sources. ${ }^{4}$ Silver can be found in low levels in many tissues, ${ }^{4-7}$ but without any clear physiologic function. Dermal exposure to high doses of silver causes argyria and mild allergic responses. ${ }^{8}$ but the toxicity profile of dermal exposure to nanosilver with acute and subchronic treatment has not yet been identified.

Silver has been used as an antimicrobial agent for a long time in the form of metallic silver and silver sulfadiazine ointments. ${ }^{9}$ However, it has recently been 
reported that nanosilver in the form of colloidal silver has been used for more than 100 years and has been registered as a biocidal material in the United States since $1954 .{ }^{10}$ Silver nanoparticles have recently been recognized as antimicrobial agents and are finding diverse medical applications such as silver-based dressings and, silver-coated medical devices. ${ }^{11,12}$ This nanoparticle can damage bacterial cell walls and cause cell death. ${ }^{13}$ Although nanosilver magnifies the therapeutic effects of silver, its safety profile has remained controversial compared with silver compounds. Because of the importance of dermal exposure to nanosilver in different health products we compared the dermal toxicity of nanosilver and silver nitrate $\left(\mathrm{AgNO}_{3}\right)$ in the guinea pig by acute and subchronic tests.

\section{Materials and methods}

Silver nanoparticles

Silver nanoparticles were purchased from QuantumSphere Inc., (Santa Ana, CA). Three different aqueous solutions $(100,1000$, and 10,000 $\mu \mathrm{g} / \mathrm{mL})$ were provided by Dr K Gilani in the Pharmaceutics Lab., Faculty of Pharmacy, Tehran University of Medical Sciences.

\section{Experimental animals and housing conditions}

Forty-eight experimental male Hartley albino guinea pigs were obtained from the Pasteur Institute of Iran at five to six weeks of age and 350 to $450 \mathrm{~g}$ body weight. All guinea pigs were housed in stainless steel cages and allowed to adapt to the conditions of the animal house for 14 days before the experiments. The animals were maintained on a 12 hour dark/light cycle at about $22 \pm 3^{\circ} \mathrm{C}$ and allowed free access to a standard laboratory diet, vitamin $\mathrm{C}$, and tap water ad libitum during the experiments. The 48 animals were randomly divided to eight treatment groups of six animals each. Three groups were allocated to an acute dermal toxicity assessment and the other five to a subchronic dermal toxicity assessment. All animal studies were conducted according to the US National Institute of Health (NIH publication no. 85-23, revised 1985) guidelines.

\section{Transmission electron microscopy and X-ray diffraction tests}

The extent and size of silver nanoparticles were determined by transmission electron microscopy (TEM) and X-ray diffraction (XRD) using standard equipment (Siemens with $\mathrm{Cu}$ source, $40 \mathrm{kV}$ and $30 \mathrm{~mA}$ ). Sample patterns were determined at 5 to 75 degrees $(2 \vartheta) .{ }^{14}$

\section{Acute dermal toxicity studies}

The acute dermal toxicity test was performed in compliance with the OECD guideline 0402. After performing a toxicity test at up to $10,000 \mu \mathrm{g} / \mathrm{mL}$ on three animals, six male animals per group were used for the acute test. This preliminary study estimated the dermal LD50 of this substance and served a basis for classification and labeling of dermal nanosilver. It was the initial step for establishing the dosage regimen in the subchronic toxicity test. The Draize test was used also initially to assess primary skin irritation potential of the test material. ${ }^{15}$

The test substance at 100 and $1000 \mu \mathrm{g} / \mathrm{mL}$ and $100 \mu \mathrm{g} / \mathrm{mL}$ of a solution of $\mathrm{AgNO}_{3}$ were applied to $10 \%$ of the body surface area of experimental animals and positive control animals, respectively. Untreated portions of the body surface area of all animals served as negative controls. The shaved and rubbed areas were covered with sterile gas and fixed with cloth glue. Animals were put inside a restrainer for a period of four to five hours and the skin of each animal was studied in intervals of $1,24,48$, and 72 hours for presence of any edema, erythema, or any type of dermal change.

Observations continued for 14 days. During the first day the animals were observed frequently and then observations were made daily. Necropsy of all animals was carried out and all gross pathologic changes were studied.

\section{Subchronic dermal toxicity studies}

Thirty guinea pigs were randomly divided into five groups (six males per group) and an area $5 \mathrm{~cm} \times 5 \mathrm{~cm}$ of the back zone of each animal was shaved for treatment. Continuous back shaving was performed two to three times per week during the rest of study (13 weeks).

The shaved skin of experimental animals was rubbed five times per week with the test material at 100,1000, and $10000 \mu \mathrm{g} / \mathrm{mL}$ and skin of positive controls was rubbed with $100 \mu \mathrm{g} / \mathrm{mL}$ of $\mathrm{AgNO}_{3}$ solution; the other parts of body in all treatment groups were kept untreated as negative control. Dermal application was performed once daily for five days per week over a period of 13 weeks.

\section{Clinical examinations}

Clinical signs were observed and weights were recorded once daily in the acute study and two times per week in the subchronic study. The recording items were divided into three categories: cageside observations, and neurologic and physical examinations. 


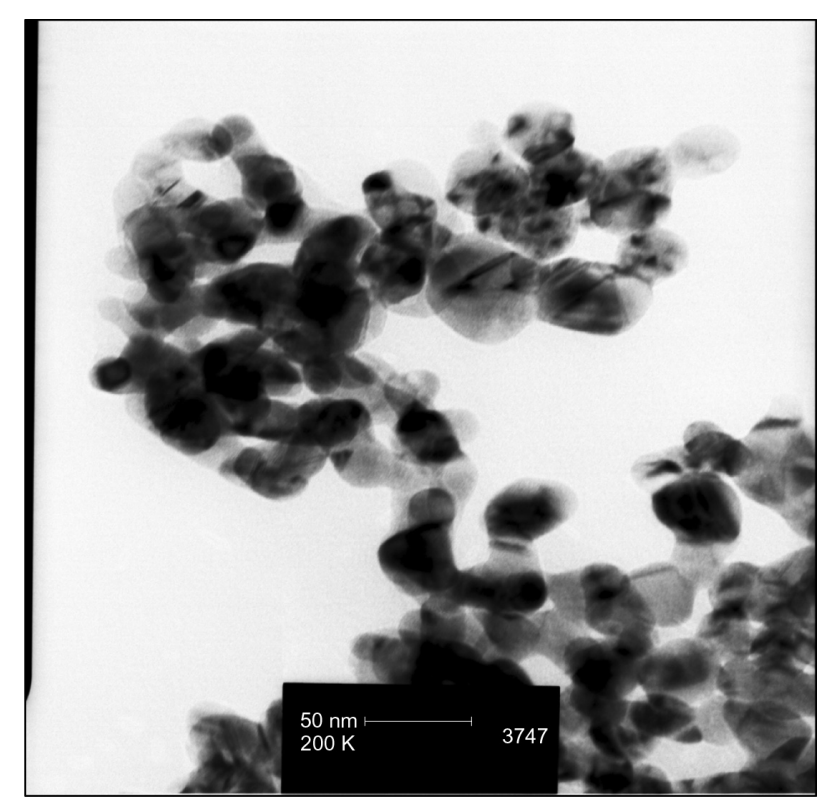

Figure I TEM image showing nanosilver particles of sizes $<100 \mathrm{~nm}$.

\section{Pathologic studies}

Tissue was removed from skin, liver, and spleen of three animals per group for histopathologic studies. The tissues were fixed in $10 \%$ buffered formalin and dehydrated in a graded series of alcohol, cleared in xylene, and embedded in paraffin wax. Multiple sections from each block were prepared at $5 \mu \mathrm{m}$ and stained with hematoxylin and eosin (H\&E) for histopathologic studies.

\section{Results \\ TEM studies}

Nanosilver particles were detected in sizes of $<100 \mathrm{~nm}$ (Figure 1).

\section{XRD examination}

Nanosilver particles were observed in the ranges of 38,44 , $64 / 5$ degrees $(2 \vartheta)$ (Figure 2).

\section{Mortality}

Because no mortality was recorded during dermal application of different concentrations of nanosilver at doses of up to $10,000 \mu \mathrm{g} / \mathrm{mL}$ in the preliminary study, we considered it to be a nontoxic agent in acute dermal exposure.

\section{Acute dermal toxicity studies}

No abnormal change was detected in the negative control (Figure 3A). In the $\mathrm{AgNO}_{3}$ group, a reduced thickness of epidermis and increased regular collagen fiber in papillary layer were observed. In addition, mononuclear inflammation was noted in this group of animals (Figure 3B).

Although a reduced thickness of epidermis and reduced thickness of papillary layer were seen in the low-dose nanosilver group $(100 \mu \mathrm{g} / \mathrm{mL})$, collagen fibers were regular (Figure 3C). Higher levels of histopathologic changes were detected in the high-dose group (Figure 3D). It seems that increased concentrations of nanosilver increased the toxic

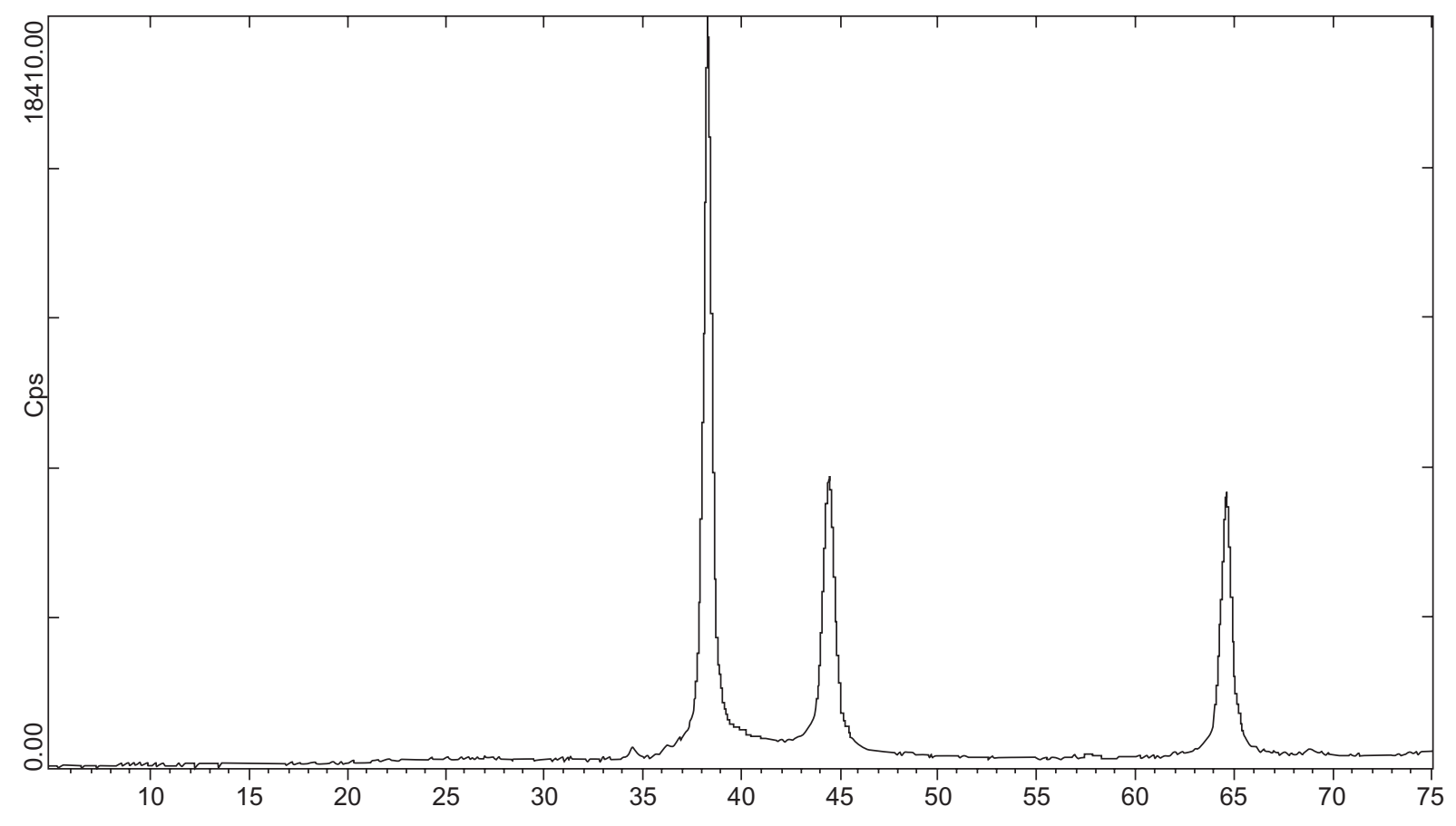

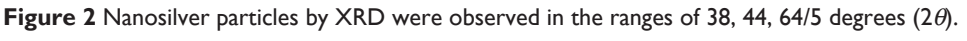



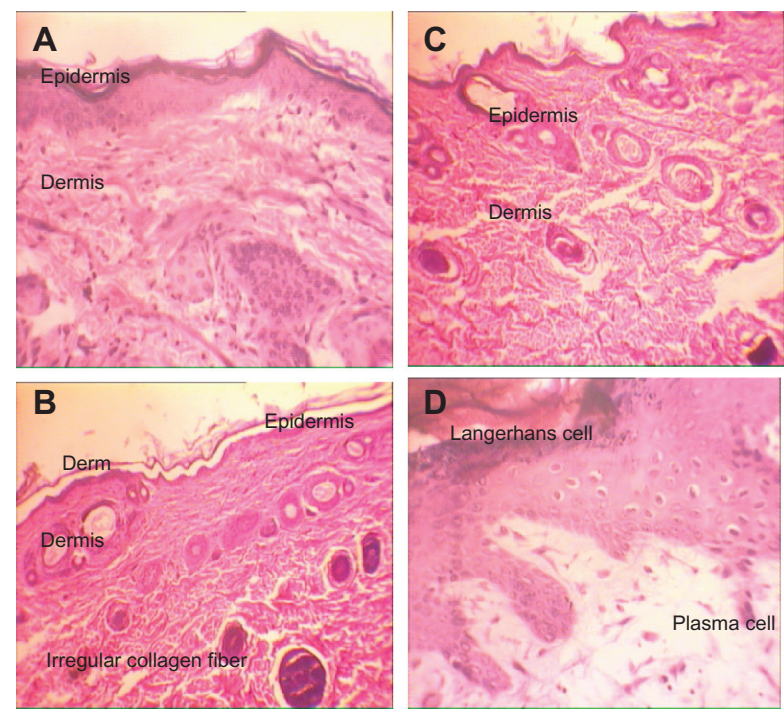

Figure $3 \mathrm{H} \& \mathrm{E}$ stained skin sections in an acute toxicity study $(\times 40)$. A) Negative control; B) $\mathrm{AgNO}_{3}$ group: reduced thickness of epidermis and increased regular collagen fiber in papillary layer and mononuclear inflammation; C) Low-dose nanosilver group with reduced thickness of epidermis, reduced thickness of papillary layer, and regular collagen fibers; D) High-dose nanosilver group with reduced thickness of epidermis, reduced thickness of papillary layer, and irregular collagen fibers.

responses of skin. Details of histopathologic abnormalities in the acute study are shown in Table 1.

\section{Subchronic toxicity test}

\section{Skin}

Similar skin inflammatory responses were recorded in all treatment groups in the subchronic study. No abnormal change was detected in the negative control (Figure 4A). In the $\mathrm{AgNO}_{3}$ group, a reduced thickness of the epidermis and papillary layer were seen. Moreover the decreased thickness of dermis and epidermis increased the numbers of Langerhans cells. Figure 4B shows inflammation, decreased thickness of the papillary layer, and increased collagen levels of the dermis layer.

In animals treated with $100 \mu \mathrm{g} / \mathrm{mL}$ nanosilver, decreased thickness of epidermis and dermis were detected, as were increased levels of Langerhans cells, inflammation, and decreased papillary layer with regular collagens fibers (Figure 4C).
In animals treated with a $1000 \mu \mathrm{g} / \mathrm{mL}$ of nanosilver, a reduced thickness of epidermis and dermis were seen, too. Increased levels of Langerhans cells and round cells, decreased papillary layer with regular collagen fibers and inflammation, and acidophilic cytoplasm in muscle fibers with inflammation were observed in endomysium. In addition some muscle fibers were surrounded by macrophages (Figure 4D).

In the animals treated with $10,000 \mu \mathrm{g} / \mathrm{mL}$ nanosilver, muscle fibers with acidophilic cytoplasm were surrounded by macrophages. In addition to degenerative fibers, increased levels of macrophage in endomysium were observed with inflammation. All observed toxic skin responses were dose- and time-dependent, which means that greatest histopathologic changes were seen in the $10,000 \mu \mathrm{g} / \mathrm{mL}$ group in the 13 -week study and the lowest in the $100 \mu \mathrm{g} / \mathrm{mL}$ group in the acute test (Figure 4E). All details of histopathologic changes in the subchronic test are listed in Table 2A.

\section{Liver}

In the $\mathrm{AgNO}_{3}$ and nanosilver groups, destruction of hepatocyte cords was seen but in the test groups this pattern was magnified by increased nanosilver concentrations. Moreover, overproduction of Kupffer cells and degeneration of hepatocytes were seen and increased with increasing nanosilver concentrations in the test groups (Figures 6B-E). Necrosis was observed only at the highest nanosilver concentration $(10,000 \mu \mathrm{g} / \mathrm{mL})$. Observed histopathologic changes clearly showed necrosis at the maximum nanosilver concentration. Thus, the results suggest a dose-dependent hepatotoxic effect of nanosilver by dermal exposure. More details on histopathologic changes of the liver are listed in Table $2 \mathrm{C}$.

\section{Spleen}

Red capsules and white pulp were seen regularly in the spleens of the control group without any abnormal change or inflammation (Figure 5A). Red capsules were thinner in the $\mathrm{AgNO}_{3}$ group with inflammation and white pulp hypertrophy (Figure 5B). In the low-dose $(100 \mu \mathrm{g} / \mathrm{mL})$ group, red capsules were much thinner, with signs of inflammation, accumulation of red blood cells, and white pulp atrophy

Table I Dermal histopathologic changes in acute study

\begin{tabular}{llllll}
\hline Group & Inflammation & Round cell & Clear cell & Reduced epidermis & Reduced papillary \\
\hline Control & - & - & - & - & - \\
$\mathrm{AgNO}_{3}$ & $+*$ & + & - & + & - \\
Nanosilver $100 \mu \mathrm{gL}$ & + & + & + & + & + \\
Nanosilver $10,000 \mu \mathrm{gg} / \mathrm{mL}$ & + & $++^{* *}$ & ++ & ++ & ++ \\
\hline
\end{tabular}



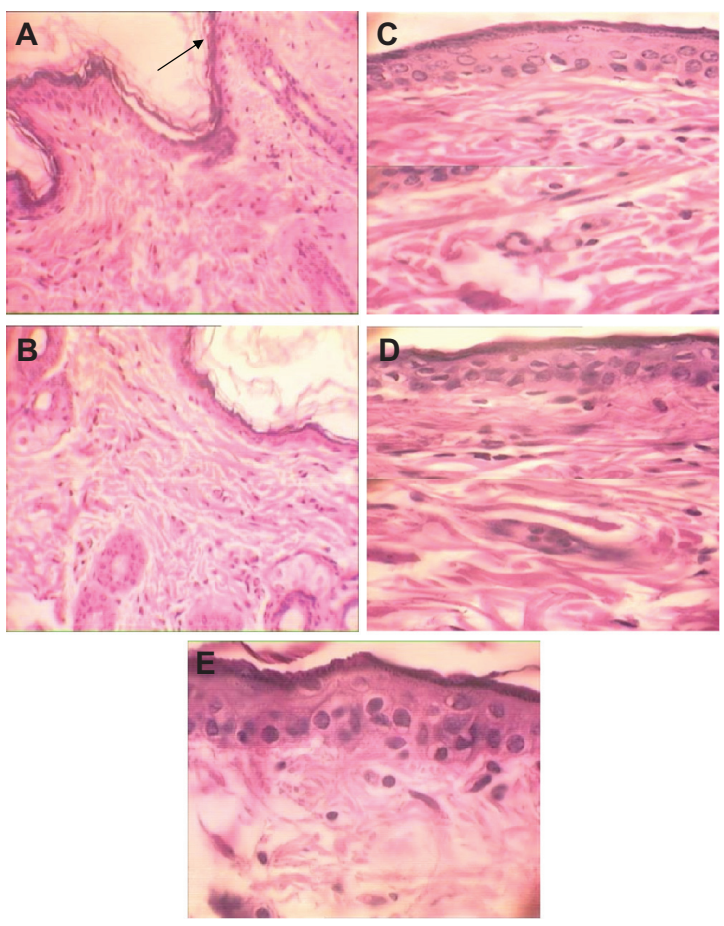

Figure $4 \mathrm{H} \& \mathrm{E}$ stained skin sections in subchronic toxicity $(\times 40)$. A) Normal skin in control group; $\mathbf{B}) \mathrm{AgNO}_{3}$ group with reduced thickness of dermis and epidermis, increased Langerhans cells, inflammation, decreased thickness of papillary zone layer, and increased collagen levels of dermis layer; C) Skin abnormalities in low-dose nanosilver group; D) Skin abnormalities in high-dose nanosilver group; E) Highest level of dermal toxicity (see text for further details).

(Figure 5C). In the medium-dose $(1000 \mu \mathrm{g} / \mathrm{mL})$ group the same pattern was repeated (Figure 5D). The highest levels of red pulp inflammation, white pulp atrophy, and thinnest capsules were seen in the high-dose group, but white pulp hypertrophy was a specific response to $\mathrm{AgNO}_{3}$, not to any nanosilver dose (Figure 5B). More details on histopathologic changes of the spleens are shown in Table $2 \mathrm{C}$.

\section{Discussion}

Nanosilver has become one of the most widely used nanomaterials in consumer products because of its antimicrobial and antiseptic properties. Because of public concern over the potential adverse effects of nanosilver, ${ }^{16}$ we assessed the toxicity potentials of different concentrations of nanosilver by dermal application because our knowledge of toxicology has been derived only from studies on administration of nanosilver inhalational ${ }^{1}$ or by mouth. ${ }^{17}$ In these previous studies, animals exposed to nanosilver showed minimal pulmonary inflammation or cytotoxicity following subacute exposures but longer-term exposures with higher body burdens of nanosilver are needed to ensure that there are no chronic effects and to evaluate possible translocation of nanosilver to other organs.

The present study clearly showed that dermal contact with nanosilver may cause histopathologic abnormalities of the skin, liver, and spleen of animals, which could be magnified by increased concentrations over longer-term exposures. The present study has emphasized also that subchronically treated animals exhibit higher dermal, hepatic, and immunological toxicity signs compared with acutely treated animals.

One of the classical toxic responses to the silver is argyria, which was reported for the first time by Blumberg and Carey in a woman who had ingested a total dose of $6.4 \mathrm{~g}$ silver nitrate over a 1-year period of time and showed argyria symptoms after the first six months of exposure. ${ }^{18}$ Rosenman et al reported also respiratory irritation, abdominal pain, and decreased night vision in workers exposed to $\mathrm{AgNO}_{3}$ and silver oxide dusts over one to ten years. ${ }^{4}$ They later showed that occupational exposure to silver compounds in a group of workers may cause respiratory irritation, decreased night vision, abnormal rise in N-acetyl-B-D glucoseaminidase, and decreased creatinine clearance. ${ }^{19}$ Discoloration of the conjunctiva and cornea in some workers was reported after inhalational exposure. ${ }^{20}$ Williams et al, in a case study of a 51-year-old man exposed to silver compounds, showed corneal and conjunctival argyrosis. ${ }^{21}$ Chang et al recorded a case study of a 59-year-old man who was distressed from dermal and face color change. He had ingested colloidal silver two to three times per year for two years and showed endocrine disruptions such as hyperlipidemia, hypertension, and diabetes as well as blue-grey facial signs. ${ }^{22}$ Neurologic symptoms are an unusual consequence of silver toxicity which

Table 2A Dermal histopathologic changes in subchronic test

\begin{tabular}{|c|c|c|c|c|c|c|}
\hline Group & Inflammation & Round cell & Clear cell & $\begin{array}{l}\text { Decreased } \\
\text { epidermis }\end{array}$ & $\begin{array}{l}\text { Decreases } \\
\text { collagen fiber }\end{array}$ & $\begin{array}{l}\text { Decreased lamina } \\
\text { propria attachments }\end{array}$ \\
\hline Control & - & - & - & - & - & - \\
\hline $\mathrm{AgNO}_{3}$ & + & - & + & + & + & - \\
\hline Nanosilver $100 \mu \mathrm{g} / \mathrm{mL}$ & + & - & + & + & + & - \\
\hline Nanosilver $1000 \mu \mathrm{g} / \mathrm{mL}$ & + & + & + & + & ++ & - \\
\hline Nanosilver $10,000 \mu \mathrm{g} / \mathrm{mL}$ & + & ++ & ++ & ++ & ++ & ++ \\
\hline
\end{tabular}

Notes: Severe $(+++)$; moderate $(++)$; mild $(+)$; none $(-)$. 
Table 2B Liver histopathologic changes in subchronic test

\begin{tabular}{llllll}
\hline Group & Inflammation & Thin capsule & White pulp atrophy & $\begin{array}{l}\text { Red pulp } \\
\text { inflammation }\end{array}$ & $\begin{array}{l}\text { White pulp } \\
\text { hypertrophy }\end{array}$ \\
\hline Control & - & - & - & - & - \\
$\mathrm{AgNO}_{3}$ & + & + & - & + & + \\
Nanosilver $100 \mu \mathrm{g} / \mathrm{mL}$ & + & + & + & + & - \\
Nanosilver $1000 \mu \mathrm{g} / \mathrm{mL}$ & + & + & + & + & - \\
Nanosilver $10,000 \mu \mathrm{mg} / \mathrm{mL}$ & + & ++ & ++ & ++ & - \\
\hline
\end{tabular}

Notes: severe $(+++)$; Moderate $(++)$; mild (+); none $(-)$.

was recently reported in a 75-year-old man who had a history of self-medication with colloidal silver and presented with myoclonic seizures. ${ }^{23}$

Our study clearly showed that the toxic effects of nanosilver depend on the route of administration. Moreover dose- and time-dependent toxic effects of nanosilver via dermal application in skin, liver, and spleen of male guina pigs were completely different from what has been seen after clinical poisoning with silver salts via inhalational or oral routes of administration.

Some reports have proved that many medical devices loaded with silver could release silver ions $\left(\mathrm{Ag}^{+}\right)$which could be translocated through the blood circulation and accumulate in some organs such as the liver and kidney. It may induce hepatotoxicity or renal toxicity and may lead to death in some cases of extreme exposure to a certain dose of $\mathrm{Ag}^{+} .{ }^{24}$ We have shown that silver nanoparticles with properties similar to those of $\mathrm{Ag}^{+}$could be translocated in the body and cause histopathologic changes in the liver and spleen unlike those caused by $\mathrm{AgNO}_{3}$ given by the same route of administration. For example, mononuclear inflammation was noted for $\mathrm{AgNO}_{3}$-treated animals only, whereas reduced epidermal thickness and thickness of papillary layer were seen after administration of different concentrations of nanosilver in our acute study.

Braydich-Stoll et a ${ }^{25}$ reported potential cytotoxicity of nanosilver in vitro. They used nanosilver in different concentrations on mammalian stem cells and showed apoptosis and necrosis in cells exposed to $\geq 10 \mu \mathrm{g} / \mathrm{mL}$ nanosilver. Mitochondrial function and cell viability were reduced by silver nanoparticles at concentrations of 1 to $5 \mu \mathrm{g} / \mathrm{mL} .{ }^{25}$ We used doses of 10,000 , 1000 , and $100 \mu \mathrm{g} / \mathrm{mL}$ solutions without recording any sign of mortality. Although the concentrations of nanosilver were high and unrealistic, to our knowledge this is the first study on dermal and systemic toxicity of nanosilver in acute and subchronic treatment. It is necessary to conduct the same study with lower doses and find the NOAEL (no observable adverse effect level) of nanosilver by dermal application.

\section{Conclusion}

The target organs for silver nanoparticles were found to be the skin, liver, and spleen in the male guinea pig after dermal application. Although a NOAEL of $30 \mathrm{mg} / \mathrm{kg}$ and LOAEL (lowest observable adverse effect level) of $125 \mathrm{mg} / \mathrm{kg}^{17}$ were suggested for oral administration of silver nanoparticles in the rat, at doses of $0.1 \mathrm{mg} / \mathrm{kg}(100 \mu \mathrm{g})$ was not a safe dose for dermal application. Although no sign of mortality was detected in any of the treatment groups, significant dose-dependent histopathologic changes were found in all treatment groups compared with controls. The present results indicate that exposure to $>0.1 \mathrm{mg} / \mathrm{kg}$ of silver nanoparticles may result in slight liver, spleen, and skin damage. It could be concluded from this study that the toxicity profile of nanosilver differs from that of silver even when given by the same route of administration. The results suggest that it is necessary to determine the association between the period of exposure and histopathologic changes with lower doses over

Table 2C Histopathologic changes of the spleen in subchronic test

\begin{tabular}{|c|c|c|c|c|c|c|}
\hline Group & Inflammation & Kupffer cell & $\begin{array}{l}\text { Limited pale } \\
\text { destruction }\end{array}$ & $\begin{array}{l}\text { Hepatic cord } \\
\text { destruction }\end{array}$ & Necrosis & $\begin{array}{l}\text { Hepatocyte } \\
\text { degeneration }\end{array}$ \\
\hline Control & - & - & - & - & - & - \\
\hline $\mathrm{AgNO}_{3}$ & + & ++ & ++ & ++ & - & ++ \\
\hline Nanosilver $100 \mu \mathrm{g} / \mathrm{mL}$ & + & + & + & + & - & + \\
\hline Nanosilver $1000 \mu \mathrm{g} / \mathrm{mL}$ & ++ & ++ & ++ & ++ & - & ++ \\
\hline Nanosilver $10,000 \mu \mathrm{g} / \mathrm{mL}$ & ++ & ++ & +++ & +++ & + & +++ \\
\hline
\end{tabular}

Notes: Severe (+++); moderate (++); mild (+); none $(-)$. 

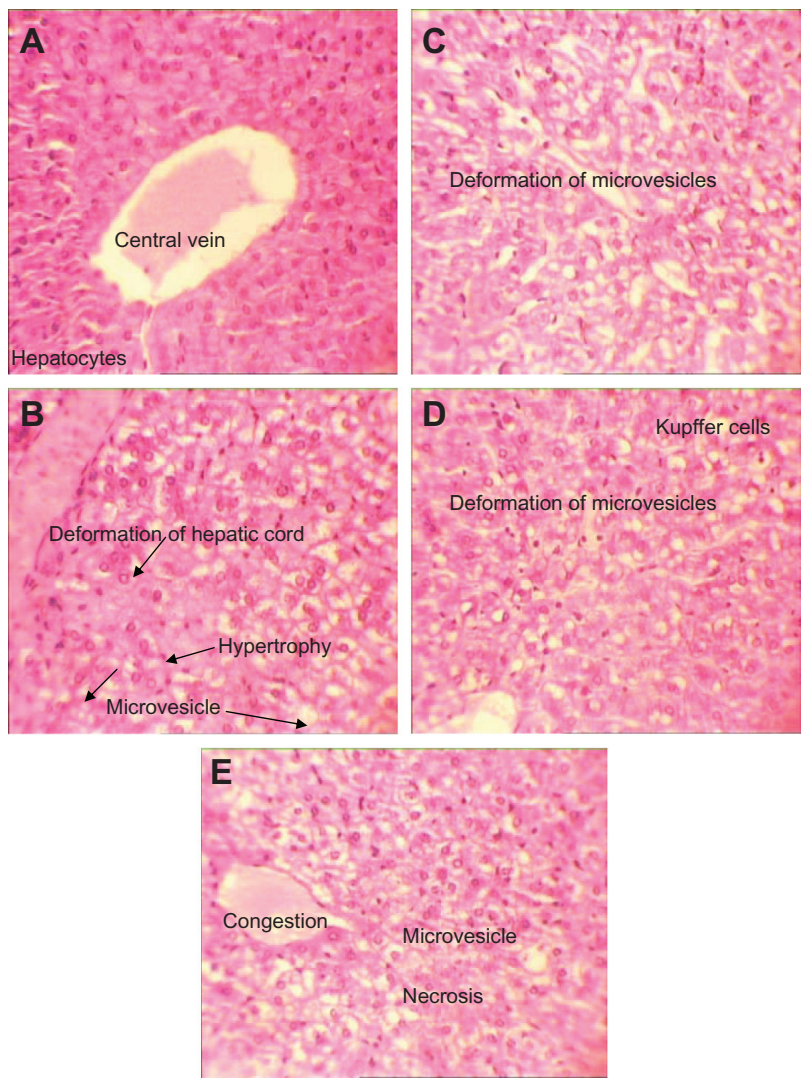

Figure 5 H\&E stained liver sections in subchronic toxicity $(\times 40)$. A) Normal liver in control group; B) $\mathrm{AgNO}_{3}$ group with hepatic cord deformation; C) Overproduction of Kupffer cells and degeneration of hepatocytes in low-dose nanosilver group; D) Overproduction of Kupffer cells and degeneration of hepatocyte in medium-dose nanosilver group; E) Liver necrosis in nanosilver high-dose group.

different time periods. The effect of particle shape and size on the toxicity profile of nanosilver administered by different routes should be determined in future studies.

\section{Disclosure}

The authors declare no conflicts of interest.

\section{References}

1. Stebounova LV, Adamcakova-Dodd A, Kim JS, et al. Nanosilver induces minimal lung toxicity or inflammation in a subacute murine inhalation model. Part Fibre Toxicol. 2011;8(1):5.

2. Teodoro JS, Simões AM, Duarte FV, et al. Assessment of the toxicity of silver nanoparticles in vitro: A mitochondrial perspective. Toxicol In Vitro. 2011 Jan 11. [Epub ahead of print].

3. Weast RC, Spadaro JA, Becker RO, et al. Handbook of Chemistry and Physics, 69th ed. Boca Raton, FL: CRC Press, Inc.; 1988-1989: (B)127-128.2.

4. Rosenman KD, Moss A, Argyria KS. Clinical implications of exposure to silver nitrate and silver oxide. J Occup Med. 1979;21:430-435.

5. Wan AT, Conyers RA, Coombs CJ, et al. Determination of silver in blood, urine, and tissues of volunteers and burn patients. Clin Chem. 1991;37:1683-1687.

6. Hollinger MA. Toxicological aspects of topical silver pharmaceuticals. Crit Rev Toxicol. 1996;26:255-260.

7. Sue YM, Lee JYY, Wang MC, et al. Generalized argyria in two chronic hemodialysis patients. Am J Kidney Dis. 2001;37:1048-1051.
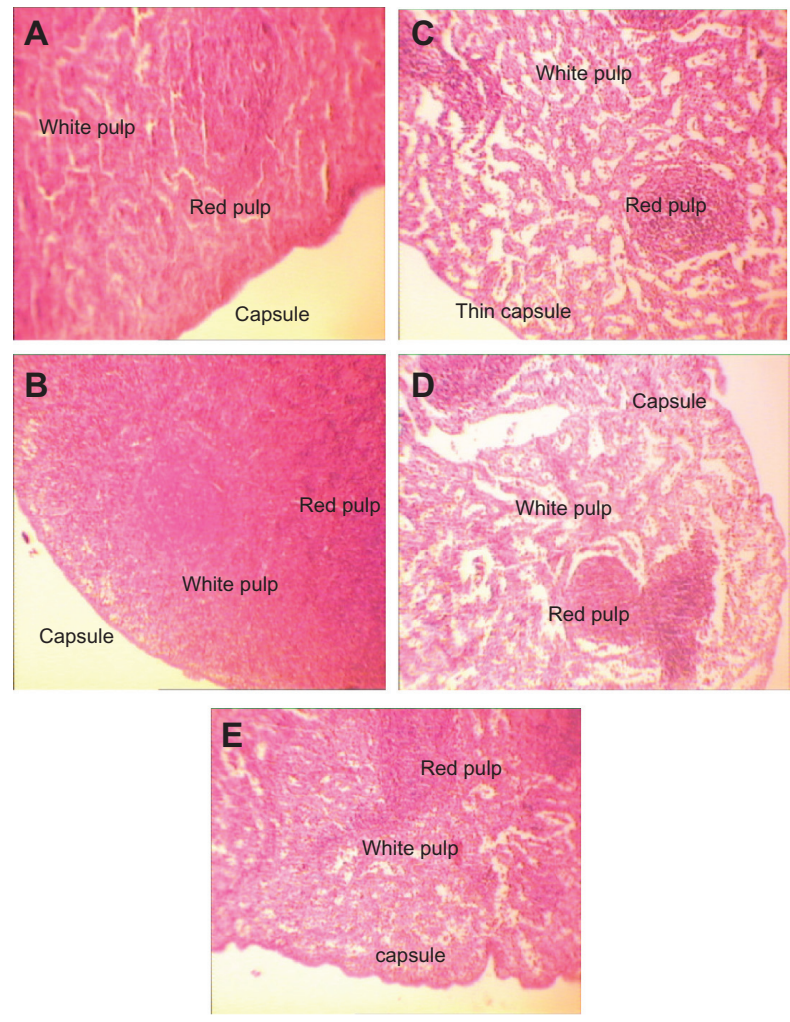

Figure $6 \mathrm{H} \& \mathrm{E}$ stained spleen sections in subchronic toxicity study $(\times 40)$. A) Normal spleen in control group. B) Thin red capsule with inflammation and white pulp hypertrophy in $\mathrm{AgNO}_{3}$ group; C) Thin capsules with inflammation, accumulation of red blood cells (RBC), and white pulp atrophy in low-dose nanosilver group; D) Thin capsules with inflammation, accumulation of RBC, and white pulp atrophy in medium-dose nanosilver group; E) The highest levels of red pulp inflammation, white pulp atrophy, and thinnest capsule in high-dose nanosilver group.

8. Stokinger HE, Silver. In: Clayton GD, Clayton E, editors. Patty's Industrial Hygiene and Toxicology, vol. 2A. 3rd ed. New York: John Wiley \& Sons; 1981:1881-1894.

9. Monteiro DR, Gorup LF, Takamiya AS, Ruvollo-Filho AC, de Camargo ER, Barbosa DB. The growing importance of materials that prevent microbial adhesion: antimicrobial effect of medical devices containing silver. Int $J$ Antimicrob Agents. 2009;34:103-110.

10. Nowack B, Krug HF, Height M. 120 years of nanosilver history: implications for policy makers. Environ Sci Technol. 2011 Jan 10. [Epub ahead of print].

11. Park SH, Im JH, Im JW, Chun BH, Kim JH. Absorption kinetics of Au and $\mathrm{Ag}$ nanoparticles on functionalized glass surfaces. Microchem J. 1999;63:71-91.

12. MTR Uses Nano Technology to Enhance Hygiene Levels. September 29, 2006.

13. Soni I, Salopek-Bondi B. Silver nanoparticles as antimicrobial agent: a case study on E. coli as a model for Gram-negative bacteria. J Colloid Interface Sci. 2004;275:1770-1782.

14. Amit Gupta, et al. Generation of C60 nanoparticle aerosol in high mass concentrations. J Aerosol Sci. 2007;38:592-603.

15. Carbone L. What Animals Want Expertise and Advocacy in Laboratory Animal Welfare Policy. Oxford University Press; 2004:63.

16. Benn T, Cavanagh B, Hristovski K, Posner JD, Westerhoff P. The release of nanosilver from consumer products used in the home. J Environ Qual. 2010;39:1875-1882.

17. Kim YS, Song MY, Park JD, et al. Subchronic oral toxicity of silver nanoparticles. Part Fibre Toxicol. 2010 6;7:20. 
18. Blumberg H, Carey TN. Argyremia: Detection of unsuspected and obscure argyria by the spectrographic demonstration of high blood silver. J Am Med Assoc. 1934;103:1521-1524.

19. Rosenman KD, Seixas N, Jacobs I. Potential nephrotoxic effects of exposure to silver. $J$ Ind Med. 1987;44:267-272.

20. Moss AP, Sugar A, Hargett NA, et al. The ocular manifestations and functional effects of occupational argyrosis. Arch Opthhalmol. 1979;97:906-908.

21. Williams N. Longitudinal medical surveillance showing lack of progression of argyrosis in a silver refiner. Occup Med. 1999;49:397-399.
22. Chang ALS, Khosravi V, Egbert B. A case of argyria after colloidal silver ingestion. J Cutan Pathol. 2006;33:809-811.

23. Tang J, Xi T. Status of biological evaluation on silver nanoparticles. Sheng Wu Yi Xue Gong Cheng Xue Za Zhi. 2008;25:958-961.

24. Stepien K, Morris R, Brown S, Taylor A, Morgan L. Unintentional silver intoxication following self-medication: an unusual case of corticobasal degeneration. Ann Clin Biochem. 2009;46:520-522.

25. Braydich Stolle L, Hussain S, Schlager JJ, Hofmann MC. In vitro cytotoxicity of nanoparticles in mammalian germLine in stem cell. Toxicol Sci. 2005;88:412-419.

\section{Publish your work in this journal}

The International Journal of Nanomedicine is an international, peerreviewed journal focusing on the application of nanotechnology in diagnostics, therapeutics, and drug delivery systems throughout the biomedical field. This journal is indexed on PubMed Central, MedLine, CAS, SciSearch $\AA$, Current Contents ${ }^{\circledR} /$ Clinical Medicine,
Journal Citation Reports/Science Edition, EMBase, Scopus and the Elsevier Bibliographic databases. The manuscript management system is completely online and includes a very quick and fair peer-review system, which is all easy to use. Visit http://www.dovepress.com/ testimonials.php to read real quotes from published authors. 